\title{
Morphological variation of head and face shapes in 17-25 years old adult population of Nepal
}

\author{
SHAH, S. * and KOIRALA, S \\ Department of Human Anatomy, BP Koirala Institute of Health Sciences Dharan-18, Koshi, Nepal \\ ${ }^{*}$ E-mail: San230dip@yahoo.com
}

\begin{abstract}
Introduction: Cephalic Index and Prosopic Index are very useful anthropometric tool to find out racial and sexual differences and also give a clue to genetic transmission of inherited characteristics from parents to their offspring. Materials and Methods: A descriptive non-interventional cross-sectional study was conducted on normal undergraduate medical students of Nepalese origin from BP Koirala Institute of Health Sciences, Nepal on September 2012. A total of 313 (male $=186$ and female $=127$ ) Nepalese young adult students with their ages ranging from 17-25 years were included for the study after taking permission from institutional ethical board and committee. All the measurements were carried out after careful palpation of the head for anatomical landmarks and measurements were taken to the nearest $1 \mathrm{~mm}$. Results obtained were presented as mean and standard deviation. Independent student $t$ test and anova test was applied to find out the gender, geographical and ethnic differences. A "p" value of $<0.05$ was considered to indicate statistical significance. Results: The head and face form of males were hyperbrachicephalic and mesoprosopic respectively and of females were mesocephalic and leptoprosopic respectively.The head and face form of Tibeto-Nepalese were hyperbrachicephalic and mesoprosopic; of Indigenous were brachiocepalic and mesoprosopic and of Indo-Nepalese were mesocephalic and leptoprosopic respectively . Conclusion: Thus the racial factor, gender, geographical and regional variations influences the craniofacial anthropometry especially head and faces form.
\end{abstract}

Keywords: anthropometry, craniofacial, genetic, index.

\section{Introduction}

Craniofacial anthropometry is a technique used in physical anthropometry comprising of precise and systematic measurement of the bones of the human skull. Cephalic Index (CI) and Prosopic Index(PI) are very useful anthropometric tool to find out racial and sexual differences and also give a clue to genetic transmission of inherited characteristics from parents to their offspring. (KOLAR and SALTER, 1997). Bodily measurements are the mainstay of anthropological research; however racial and sometimes ethnic variations do exist between these measurements because human body dimensions are affected by ecological, biological, geographical, racial, gender, age related and nutritional factors (RAJI et al., 2010).

Nepalese society is ethnically diverse and complex in phenotype (physical characteristics) and culture ranging between Indian to Tibetan population.Political scientists, Joshi and Rose, broadly classify the Nepalese population into three major ethnic groups in terms of their origin: Indo-Nepalese(IND), Tibeto-Nepalese(TN) and Indigenous(IN). In case of first two groups, the direction of their migration and Nepal's landscapes appeared to have led to their vertical distribution. The first group, comprising those of Indo-Nepalese origin, inhabit the more fertile lower hills, river valleys and Terai plains adjoining boundary of India.The second major group consist of communities of Tibeto-Nepalese origin occupying the higher hills from west to east.The third and much smaller group comprises of a number of tribal communities, who represent both the characteristics of Indo-Nepalese and Tibeto-Nepalese (JOSHI and ROSE, 1991).
In view of differences observed in other studies, based on racial and ethnic differences, this study was designed to determine the variation of shapes of head and face present in young adult population of Nepal. This study will provide a data base of craniofacial measurements that will help surgeons to have knowledge with wide range of craniofacial dimensions which would be helpful in craniofacial reconstruction Surgery.

\section{Materials and Methods}

\subsection{Study design and setting}

A descriptive non-interventional cross-sectional study was conducted on normal undergraduate medical students of Nepalese origin from BP Koirala Institute of Health Sciences (BPKIHS), Nepal on September 2012. These students were selected because of easy availability with wide variety among races, castes and geographical locations of Nepal.

\subsection{Eligibility criteria and data collection}

A total of 313 (male=186 and female=127) Nepalese young adult students with their ages ranging from 17-25 years were included for the study after taking permission from institutional ethical board and committee of ethical of BPKIHS. Subjects showing any craniofacial injury or deformity and students from foreign nations were excluded from the study. Prior to study, purpose of this study was explained and informed consent was taken from each participant and was also assured about the maintaining of anonymity. 


\subsection{Craniofacial measurements}

The subjects were asked to sit on a chair in relaxed condition with their heads in anatomical position and the measurements taken using a spreading calliper using standard anatomical landmarks (LOBO, CHANDRASEKHAR and KUMAR, 2005). All the measurements were carried out after careful palpation of the head for anatomical landmarks and measurements were taken to the nearest $1 \mathrm{~mm}$.

Head length - From glabella to the Inion,

Head width - Distance between the parietal eminences

Face length - Distance from the nasion to the gnathion

Face width - Distance between the zygomatic arches

Cranial index (CI) and Prosopic index (PI) were calculated by the following formulae respectively.

$$
\begin{aligned}
& \mathrm{CI}=\frac{\text { Head Width }}{\text { Head Length }} \times 100 \\
& \mathrm{PI}=\frac{\text { Face Length }}{\text { Face Width }} \times 100
\end{aligned}
$$

Depending upon these indices the types of head and face shapes were classified as given below (PANERO, 1979):

$\begin{array}{lc}\text { Head shape } & \text { Range of Cephalic Index }(\mathrm{CI})(\%) \\ \text { Dolicocephalic } & <74.9\end{array}$

Mesocephalic

(average head)

75-79.9

Brachycephalic

(broad and short head)

80-84.9

Hyperbrachycephalic

(very broad and short head)

85-89.9

Face Shape

Hypereuriprosopic

(very broad face)

Euriprosopic (broad face)

Mesoprosopic (round face)

Leptoprosopic (long face)

Hyperleptoprosopic (very long face)

Range of Prosopic Index (PI) (\%)

$<79.9$

80-84.9

85-89.9

90-94.9

$>95$
Table 2 showed the comparison of all measured parameters with gender differences. The head and face form of males were hyperbrachicephalic and mesoprosopic respectively and of females were mesocephalic and leptoprosopic respectively.

Table 3 showed the comparison of all measured parameters with ethnic differences. The head and face form of Tibeto-Nepalese were hyperbrachicephalic and mesoprosopic; of Indigenous were brachiocepalic and mesoprosopic and of Indo-Nepalese were mesocephalic and leptoprosopic respectively .

Table 4 showed the comparison of all measured parameters with geographical differences. The head and face form of students origin from hilly areas were brachiocepalic and mesoprosopic and of students from terai areas were mesocephalic and leptoprosopic respectively .

Table 5 showed the comparison of all measured parameters with regional differences. The head and face form of students origin from eastern and central region of Nepal were mesocephalic and mesoprosopic and of students from western region were brachiocepalic and mesoprosopic respectively.

\section{Discussion}

The mean CI percentage in the present study was found to be lower than study conducted among 267 subjects of Gurung village in Nepal (male=83.1 and female=84.6) showing the brachiocephalic head form (LOBO, CHANDRASEKHAR and KUMAR, 2005); study conducted in India with CI 80.42 (SHAH and JADHAV, 2004) and in Chile with 81.52 (DEL SOL, 2005) but was found to be higher than the study conducted in Theran, Iran revealing mean CI as 75.0 (ABOLHASANZADEH and FARAHANI, 2003).

The mean PI percentage in the present study was found to be lower than the study conducted in Nigeria (RAJI ET AL., 2010) among 343 subjects with PI (male=99.39 and

Table 1. Mean value of all measured parameters.

\begin{tabular}{ccc}
\hline SN & Measured parameters & Mean \\
\hline 1 & Head length & 189.75 \\
2 & Head width & 149.20 \\
3 & CI & $78.75^{*}$ \\
4 & Face length & 122.21 \\
5 & Face width & 136.29 \\
6 & PI & $89.61^{*}$ \\
\hline
\end{tabular}

*The head form and face form of all study group lies under mesocepalic and mesoprosopic category.

Table 2. Mean and SD of all measured parameters with gender differences.

\begin{tabular}{cccc}
\hline $\begin{array}{c}\text { Measured } \\
\text { parameters }\end{array}$ & $\begin{array}{c}\text { Male } \\
(\mathbf{n}=\mathbf{1 8 6})\end{array}$ & Female(n=127) & p-value* \\
\hline Head length & $190.90 \pm 11.69$ & $187.24 \pm 11.43$ & $\mathbf{0 . 0 3 4}$ \\
Head width & $149.62 \pm 6.82$ & $148.28 \pm 6.86$ & 0.188 \\
CI & $78.50 \pm 2.91$ & $79.30 \pm 4.06$ & $0.101 \mathrm{~N}$ \\
Face length & $122.24 \pm 4.98$ & $122.13 \pm 4.61$ & 0.883 \\
Face width & $136.83 \pm 4.89$ & $135.12 \pm 4.36$ & $\mathbf{0 . 0 1 5}$ \\
PI & $89.29 \pm 1.75$ & $90.31 \pm 21.94$ & $<\mathbf{0 . 0 0 1}$ \\
\hline
\end{tabular}

$\mathrm{n}=$ number of participants. ${ }^{*} \mathrm{p}$-value $<0.05=$ statistically significant difference and $>0.05=$ statistically not significant difference. 
Table 3. Mean and SD of all measured parameters with ethnic differences.

\begin{tabular}{ccccc}
\hline Measured parameters & Tibeto-Nepalese $(n=77)$ & Indigenous $(\boldsymbol{n}=82)$ & Indo-Nepalese $(\boldsymbol{n}=154)$ & $P$ value \\
\hline Head length & $176.78 \pm 7.41$ & $179.79 \pm 6.08$ & $196.23 \pm 8.85$ & $<0.001$ \\
Head width & $150.30 \pm 6.56$ & $145.73 \pm 4.95$ & $150.23 \pm 7.12$ & $<0.001$ \\
CI & $85.04 \pm 1.59$ & $81.03 \pm 2.03$ & $76.60 \pm 1.91$ & $<0.001$ \\
Face length & $115.59 \pm 3.54$ & $119.35 \pm 4.04$ & $124.65 \pm 3.27$ & $<0.001$ \\
Face width & $133.78 \pm 5.29$ & $134.27 \pm 5.01$ & $137.58 \pm 4.11$ & $<0.001$ \\
PI & $86.42 \pm 1.47$ & $88.85 \pm 1.16$ & $90.55 \pm 1.94$ & $<0.001$ \\
\hline
\end{tabular}

$\mathrm{n}=$ number of participants. ${ }^{*} \mathrm{p}$-value $<0.05=$ statistically significant difference and $>0.05=$ statistically not significant difference.

Table 4. Mean and SD of all measured parameters with geographical differences.

\begin{tabular}{|c|c|c|c|}
\hline Measured parameters & Mountain/Hilly area $(n=146)$ & Terai/Plain area $(n=167)$ & Pvalue* \\
\hline Head length & $179.00 \pm 1.41$ & $189.41 \pm 11.55$ & $<0.001$ \\
\hline Head width & $150.50 \pm 3.54$ & $149.44 \pm 6.89$ & 0.80 \\
\hline CI & $84.20 \pm 1.13$ & $77.33 \pm 1.97$ & $<0.001$ \\
\hline Face length & $113.50 \pm 4.95$ & $123.82 \pm 3.70$ & $<0.001$ \\
\hline Face width & $129.50 \pm 4.95$ & $137.46 \pm 4.18$ & $<0.001$ \\
\hline PI & $89.150 \pm 2.83$ & $90.02 \pm 1.52$ & 0.001 \\
\hline
\end{tabular}

$\mathrm{n}=$ number of participants. ${ }^{*} \mathrm{p}$-value $<0.05=$ statistically significant difference and $>0.05=$ statistically not significant difference.

Table 5. Mean and SD of all measured parameters with regional differences.

\begin{tabular}{ccccc}
\hline Measured parameters & Eastern region $(\boldsymbol{n = 1 4 5 )}$ & Central region $(\boldsymbol{n}=95)$ & Western region $(\boldsymbol{n}=73)$ & $P$ value \\
\hline Head length & $189.74 \pm 11.94$ & $190.76 \pm 12.04$ & $186.59 \pm 8.92$ & 0.348 \\
Head width & $148.62 \pm 7.07$ & $149.87 \pm 6.71$ & $150.23 \pm 5.92$ & 0.363 \\
CI & $78.43 \pm 3.23$ & $78.74 \pm 3.29$ & $80.57 \pm 3.50$ & 0.020 \\
Face length & $122.81 \pm 4.45$ & $122.19 \pm 4.88$ & $118.95 \pm 5.76$ & 0.003 \\
Face width & $136.80 \pm 4.45$ & $136.14 \pm 5.18$ & $133.95 \pm 4.78$ & 0.035 \\
PI & $89.71 \pm 1.92$ & $89.70 \pm 1.60$ & $88.81 \pm 2.20$ & 0.099 \\
\hline
\end{tabular}

$\mathrm{n}=$ number of participants. ${ }^{*} \mathrm{p}$-value $<0.05=$ statistically significant difference and $>0.05=$ statistically not significant difference.

female=97.54) in which hypereuryprosopic type of face was dominant but found to be higher than the study conducted in Iran (ZAHARA, 2006) in Sistani and Baluch group with mean PI 83.22 and 84.86 respectively showing mesoprospic type of face.

\section{Conclusion}

Thus the racial factor, gender, geographical and regional variations influences the craniofacial anthropometry especially head and faces form. It is mainly depends primary on hereditary factors though environmental factors has secondary effect on it.

Acknowledgements: The author and co-authors acknowledge the support and assistant given by the Department of Human anatomy, BP Koirala Institute of Health Sciences, Nepal; the participants and other individuals to ensure the successful completion of this study.

\section{References}

ABOLHASANZADEH, A. and FARAHANI MR. Standard international classification of head shapes of 22-24years old in Tehran. Journal of Research in Medicine, 2003, vol. 26, no. 4, p. 281-285.

DEL SOL, M. Cephalic index in a group of mapuche individuals in the IX Region of Chile. International Journal of Morphology, 2005, vol. 23, n. 3, p. 241-246. http://dx.doi.org/10.4067/S071795022005000300009 .
JOSHI, BL. and ROSE, LE. Nepal-caste and ethnicity. 1991. Available from: <http://www.photius.com/countries/nepal/society/ nepal_society_caste_and_ethnicity.html>. Access in: 6 July 2014.

KOLAR, J.C. and SALTER, EM. Craniofacial anthropometry: practical measurement of the head and face for clinical, surgical and research use. Springfield: C.C. Thomas, 1997.

LOBO, SW., CHANDRASEKHAR, TS. and KUMAR. Cephalic index of Garung Community of Nepal: an anthropometric study. Kathmandu University Medical Journal, 2005, vol. 3, n. 11, p. 263 265. PMid:18650589.

PANERO, J. Human dimension and inferior space. 1st ed. London: Architectural Press, 1979. p. 15.

RAJI, JM., GARBA, SH., NUMAN, AI., WAZIRI, MA. and MAINA, MB. Morphological evaluation of head and face shapes in a NorthEastern Nigerian population. Australian Journal of Basic and Applied Sciences, 2010, vol. 4, n. 8, p. 3338-3341.

SHAH, GV. and JADHAV, HR. The study of cephalic index in students of Gujrat. Journal of the Anatomical Society of India, 2004, vol. 53 , n. 1, p. 25-26.

ZAHARA, H. Morphological evaluation of head and face in 18-25 years old women in southeast. Iranian Journal of Medical Sciences, 2006, vol. 6, n. 3, p. 400-404. http://dx.doi.org/10.3923/ jms.2006.400.404. 